\title{
General Guidance to Writing Scientific Works
}

\author{
Walter J Gomes, Ricardo Brandau, Domingo M Braile
}

$\mathrm{T}$ he aim of this guide is to discuss aspects that should be considered when writing a scientific article. With the speed of globalization and with the inclusion of the Revista Brasileira de Cirurgia Cardiovascular / Brazilian Journal of Cardiovascular Surgery (RBCCV/BJCVS) on the CTSnet internet site (www.ctsweb.org), an improvement in the quality is an objective which needs to achieved as soon as possible in this ever renovating process.

Publication of a scientific article is the culmination of a research process. Unpublished data and information lose their relevance. The writing of a scientific manuscript must follow certain rules and conventions and thus must obey the established formats.

The correct preparation of the manuscript is fundamental for its acceptance by any scientific journal. Otherwise, all the work of planning, research of data, interpretation and writing will remain unused by its rejection. Initially it is necessary to read the "Instructions to authors" of the chosen journal. Currently, the majority of journals follow the standards designed by the Medical Editors Group in Vancouver, 1978. Details are important. And so badly written and spelling mistakes testify against the quality of the article (always check using good dictionaries). Not complying with the norms of the journal also indicates lack of care. Incomplete manuscripts and those that do not follow the norms are subject to longer delays in publishing, as they often require several revisions.

The manuscript is the written text without the final revision of the editorial board. It becomes know as a scientific article after publication.

The scientific article should be explicative and at the same time concise, as the editorial space nowadays has a high cost and the time available to readers is continuously decreasing. Nevertheless, objectivity increases comprehension and encourages more readers.

Care in the preparation of the manuscript is fundamental for its acceptance by the editorial board. If the author or authors do not take care to rewrite it according to these parameters, the work may be accepted but so many modifications will be required that the final version will be completely different from its original, adding to the loss or time and resources.

\section{Scientific language}

Short and clear - A scientific article should be clear, summarized and easy to read. Avoid very long phrases with ambiguous meanings, which make understanding difficult. Clear and always when possible, concise, are essential for a good text. It is equivocal to consider that a prolix text, padded with abbreviations or neologisms will have a greater impact in the scientific community.

Style - The style of writing is difficult to define, mainly because it is very personal. However, the employed style should be close to the style of the targeted journal.

Verb time - The verb should be in the preterit and the verb tense that is used should be the passive voice ("the test was made...", "the surgery was performed"). The use of the first person singular and plural should be avoided ("I performed...", "we managed..."). Scientific research involves neutrality, the independent knowledge of the subject and thus the author should not become involved with the experimental contents.

Objectivity of the text - During the elaboration of a scientific work, personal points of view which are subjective and that might not be based on concrete data should be avoided. Also adjectives should be sparingly used, as they are also subjective. When qualifying something using an adjective, its value comes into question and different degrees are adopted depending on the subject.

Abbreviations - Every abbreviation, between parentheses, should follow the first occurrence of the abbreviated phrase in the body of the text. The use of many abbreviations in the article is inadvisable, as this makes the text difficult to read and understand. This rule is more important in the Abstract, as here the reader wants a text that is easy to understand. 
Type -The "General information" section of the norms of the Revista Brasileira de Cirurgia Cardiovascular/Brazilian Journal of Cardiovascular Surgery requests the use of the 'Times New Roman' type. It is of fundamental importance to follow this guideline as when another type is used, there is a risk that some symbols are lost during conversion, prejudicing its comprehension and editing.

\section{The Scientific Article}

Title - The title should be wide-ranging, objective and express all the contents of the article, but at the same time concise, and should remain within the limits established by the norms of the journal. A summarized title attracts the attention of the reader more and it is a tool to encourage the reader's interested in the rest of the article. Abbreviations are not permitted in the title. (Look at "Limits for type of article" in the Instructions to Authors of the RBCCV)

Introduction - Should be short and concise, not exceeding three paragraphs. It should mention the rationale for the work, leading the reader to understand its proposal, which will be clearly stated in the objective discussed in the last past of this chapter. Every work must have an objective, which is the query that the research proposes to answer, validating the reason for its existence.

Method - Should contain information about the type of individuals studied with the demographic data and inclusion and exclusion criteria. Explain what was measured and how it was measured. Explain the techniques and tests that were used - if the details are long and complex cite published sources. Ideally the method should provide the necessary information to allow an exact replication of the study performed. The statistical methods used should be mentioned and their utilization should be explained. Also computed statistical packages used and their manufacturers must be stated (as is demanded by the majority of them) allowing the reader to analyze their validity. Statistical analysis should obey clear and explicit criteria in order to avoid any doubts or controversy in relation to the obtained data. The p-value accepted by the author for the rejection of the null hypothesis must be stated in this section. (See article about statistical analysis on page 120)

Results - This is the most important part of the work, as the obtained data speak for themselves. They should be presented in the same order as in the method. This section serves to report the data and not to discuss the data. Also avoid interpretation and qualification of the obtained results ("there was an excessive occurrence of...") or conclusions ("this technique proved to be very effective and well tolerated"). Avoid duplication of data in the text and in tables. The tables aim to facilitate presentation and not to become repetitive and to make the reading of the text more difficult.
Discussion - In this section comments, inferences and recommendations can be made as long as they are supported by the results. The initial part of the discussion should preferentially focus on analysis of the obtained data. Also comments about relevant publications on the theme should be cited, explaining the differences and similarities found. The discussion section should be ended with a conclusion, that should clearly and explicitly answer the question asked in the objective. However, the conclusion should stress the answer was obtained starting from a determined investigation, from the data derived from the results, presented using verbs in the present tense. There may be more than one conclusion, and so the conclusions should not be confused with the results.

Descriptors - It is important to include terms which facilitate the search of scientific information. With the aim of avoiding equivocate utilization of words, it is necessary to consult the following sites: DeCS Descriptors in Health Sciences (http://www.decs.bvs.br), a site which contains terms in Portuguese, Spanish and English; and MeSH - Medical Subject Headings (http:/ /www.nlm.nih.gov/mesh), with terms only in English. (See item "Second page - Abstract" in Instructions for Authors of RBCCV)

References - References related to the method and sited inferences or similar studies should be listed in the manuscript. Bibliographic reviews about the theme should not be included, only those effectively used in the preparation of the manuscript. Be careful about the maximum number of references allowed by the journal for each type of article. In preference use recent articles from the highest quality journals, from those with a greater impact and easier access.

The internet can provide a rapid and efficient method to find the scientific information. Databases are available for this purpose, among which are Medline (medline.cos.com), PubMed (www.ncbi.nlm.nih.gov/ PubMed/), Bireme (www.bireme.br) and Scielo (www.scielo.br).

Very important additional care must be taken when preparing the references section, which must follow the format demanded by the journal (normally based on the Vancouver convention). Mistakes in this section show lack of care in the elaboration of the manuscript. Confirm the accuracy of the references to avoid mistakes. The names of the periodicals should be abbreviated according to the rules of the ISO (International Standards Organization). Verify with extreme care, that all the references cited in the text appear in the Bibliographic Reference section and viceversa. (See "references" item in the Instructions for Authors of the RBCCV)

Resumo (Abstract in Portuguese) - As it is short, gives an idea of all the work and appears at the start of 
the text, the abstract is often the only part of the work to be read (this may seem painful to authors). Thus, the abstract deserves special attention from authors. It should be structured, with the exception of case reports, containing all the information that exists in the manuscript. (See the item "Manuscript sections" in Instructions for Authors of the RBCCV)

Abstract - Is a translation of the 'resumo' to English. If the author is not fluent in this language, the abstract should be corrected by a proficient professional (if possible a native speaker).

Tables - Should provide additional information to the text without redundancy as has already been mentioned. All abbreviations and expressions etc. used in the tables must be defined in the legend. Tables should follow the model shown in the Instructions for Authors and they must be completely self-explicative, in such a way that the reader does not need to read the text to understand them. Excessive use of tables makes manuscripts confused, prejudicing its ease of reading and comprehension, however, the author should be careful about their use, including only the strictly necessary. (See the example of a table in Instructions for Authors of the RBCCV)

Figures and Illustrations - Photographs and designs which have excellent quality can be included, to allow high quality graphic reproduction. In the case of photographs, it is necessary to comply with the norms of the journal in respect to the resolution. Lists should be considered as figures and follow the same rules. (See the example of the figure in the Instructions for Authors in the RBCCV)

Authors and coauthors of scientific articles are those who directly and effectively contribute in its preparation. Authorship of the scientific work should be given to those who participated in the intellectual content of the manuscript. They should have participated in 1) the conception and planning of the work, analysis and interpretation of the data; 2) writing of the original manuscript and/or its subsequent versions collaborating in its critical review and 3) approval of the final version and accepting responsibility for the information expressed in the text.
Participation in all described stages is necessary to deserve mention as a co-author. Those who only participated in data collection or in obtaining financial support for the research or only in general supervision do not participate sufficiently to be credited as coauthors. These people should be thanked at the end of the text in the acknowledgment section. We must emphasize that the main author and the coauthors are all considered authors of the article and are responsible for its content and are valorized by the work.

\section{Further Reading}

We recommend the following articles and books for those who want more information about the art of writing scientific articles. In particular we recommend the book by Professor Gilson Luiz Volpato - Publicação Científica, which is national, simple and which competently deals with all the necessary topics for the good writing of scientific works.

The book can be ordered from Santana Gráfica Editora.

Rua Prudente de Moraes, 23

CEP 18602-060- Botucatu-SP.

Tel (14) 6821-1106/Fax (14) 6823-4100.

E-mail: Santana@laser.com.br

Reyes HB, Kauffmann RQ, Andresen MH. La autoría en los manuscritos publicados en revistas biomédicas. Rev Med Chile 2000;128:363-6.

Waldhausen JA, Localio AR. The format of a paper. J Thorac Cardiovasc Surg 1996;112:209.

Meyer CA. Iniciação ao trabalho científico. Centro Universitário São Camilo 1998, São Paulo. 48 p

International Committee of Medical Journal Editors. Uniform requirements for manuscripts submitted to biomedical journals. N Engl J Med 1991;324:424-87.

Goldenberg S, Soares AL. Orientação normativa para elaboração e apresentação de teses. São Paulo, 1997 (Em disquete)

Volpato GL. Publicação científica. Santana Gráfica e Editora. 2002, Botucatu, 119 p. 